\title{
Caracterización de Pasteurella multocida subsp multocida en la neumonía porcina
}

\author{
Characterization of Pasteurella multocida subsp. multocida in swine pneumonia
}

\author{
Vera L. Yanedt A. ${ }^{1 *}$, Ortiz L. José F. ${ }^{2}$ \\ ${ }^{1}$ Microbióloga. Esp. Protección de los Alimentos. Esp. Laboratorio Clínico Veterinario. PhD. Sanidad \\ Animal y Reproducción. Docente Facultad de Ciencias Agrarias. Universidad de Pamplona. Colombia. \\ ${ }^{2}$ Microbiólogo. Esp. Protección de los Alimentos. PhD. Biología Molecular y Biotecnología. Docente \\ Facultad de Ciencias Básicas. Universidad de Pamplona. Colombia.
}

Recibido 25 de Marzo 2015; aceptado 05 de Mayo 2015

\section{RESUMEN}

A partir de 181 muestras obtenidas de pulmones de cerdos con lesiones de neumonía recolectadas en el matadero de León, durante los años 2003-2004 y de otras 76 cepas aisladas previamente, durante 1987-1988; procedentes de diversas provincias de Castilla y León, se logró caracterizar fenotípica y genotípicamente como Pasteurella multocida, para un total de 221 cepas bacterianas. Mediante la identificación bioquímica estas cepas se sub-tipificaron como subespecie multocida, siendo agrupadas en los tipos capsulares $A$ y $D$, mediante el test de sensibilidad a la hialuronidasa y de aglutinación de la acriflavina, respectivamente. En la caracterización genotípica a nivel de especie se amplificó mediante PCR la secuencia génica KMT1, e igualmente la diferenciación de los tipos capsulares $(A, B, D, E$ y $F)$ se realizó mediante el análisis de la región 2 del cromosoma, siendo estos resultados, correspondientes con la caracterización capsular $A$ y $D$.

Palabras clave: Cerdos, Neumonía, Pasteurella multocida subsp multocida, PCR.

\section{ABSTRACT}

*Autor a quien debe dirigirse la correspondencia. E-mail: yanedt.vera@unipamplona.edu.co
From 181 samples obtained from lungs with pneumonia lesions collected from pigs in the slaughterhouse in Leon, during the years 2003-2004 and 76 other previously isolated strains during 1987-1988; from various provinces of Castilla and Leon, it was possible to characterize phenotypic and genotypic as Pasteurella multocida, a total of 221 bacterial strains. By biochemical identification these subtyped strains and subspecies multocida, being grouped into the capsular types $A$ and $D$, using the test sensitivity and agglutination hyaluronidase acriflavine, respectively. In the genotypic characterization at the species level was PCR 
amplified gene sequence KMT1, and also differentiation of the capsular types ( $A$, $B, D, E$ and $F$ ) was performed using analysis region 2 of the chromosome, these being results associated with the capsular characterization a and $D$.

Keywords: Swine, Pneumonia, Pasteurella multocida subsp multocida, PCR.

\section{INTRODUCCIÓN}

Pasteurella multocida es un importante patógeno animal. En el ganado porcino, se reconoce como un patógeno oportunista que participa del desarrollo de la rinitis atrófica y del Complejo de Enfermedad Respiratoria Porcina (CERP), enfermedades que se reconocen y se detectan de forma muy evidente en los mataderos por los daños causados sobre los cornetes nasales y en los pulmones (neumonía), respectivamente. $P$. multocida hace parte del grupo HAP (Haemophilus parasuis, $H$. somnus, Actinobacillus pleuroneumoniae y Pasteurella multocida), considerado como una de las principales causas de pérdidas económicas bovinas (Nielsen y Frederiksen, 1990; Ackermann et al., 1994). Está presente en la mayoría de las explotaciones y se aísla con cierta facilidad de las fosas nasales y tonsilas de animales sanos, se disemina principalmente mediante el contacto estrecho y directo entre los animales, seguramente a través de los hábitos de oler que suponen la relación directa entre orificios nasales de unos y otros. $P$. multocida se identifica y clasifica atendiendo a criterios y características fenotípicas, tales como la morfología, patrones de fermentación de carbohidratos y propiedades serológicas, existiendo en este último aspecto, cinco tipos capsulares $(A, B, C, E$ y $F$ ) y 16 tipos somáticos (1 al 16), que permiten, en combinación, identificar los serotipos que, desde el punto de vista patógeno, se asocian con procesos específicos de los animales o el hombre (Carter y Subpronto, 1973; Carter y Rundell, 1975). Todas estas reacciones resultan útiles para diferenciar esta bacteria de otras estrechamente relacionadas, que también se encuentran involucradas en enfermedades pulmonares porcinas, tales como $A$. pleuropneumoniae y $A$. suis (Carter y Subpronto, 1973; Rhoades y Rimler, 1989; Sneath y Stevens, 1990; Garrity, 2005). Como las condiciones de cultivo pueden influir sobre la expresión de los caracteres bioquímicos, en los últimos años, la aplicación de técnicas moleculares basadas en el estudio de los ácidos nucleicos, han facilitando la detección e identificación y encuadre taxonómico de $P$. multocida. Una de estas alternativas, es el uso de la reacción en cadena de la polimerasa (PCR), que mediante la amplificación de una secuencia específica de $A D N$ ha permitido la detección de Pasteurella multocida en cultivos mixtos o muestras clínicas de origen porcino, demostrando alta sensibilidad y eficacia (Kasten et al., 1997a; Townsend et al., 1998, Petersen et al., 2001; Townsend et al., 2001). El presente estudio se plantea con el objetivo de comparar los métodos bioquímicos y no serológicos con técnicas moleculares empleados en la identificación de aislados de $P$. multocida tomados a partir de muestras clínicas de cerdos.

\section{MATERIALES Y MÉTODOS}

\section{Cepas bacterianas}

La obtención de las muestras, a partir de pulmones de cerdos procedentes de diferentes localidades de España, se llevó a cabo en la planta de sacrificio de 6 la ciudad de León, provincia de Castilla y León, durante el periodo 2003-2004. Las muestras fueron tomadas mediante hisopados, recolectándose el 
exudado que presentaba los pulmones de cerdos, en áreas donde se evidenciaban lesiones neumónicas. Estas fueron sembradas en el medio selectivo para Pasteurella multocida (Avril et al., 1990), incubadas durante 24 horas a $37^{\circ} \mathrm{C}$ y bajo una atmósfera modificada con un $5 \%$ de $\mathrm{CO}$, (Anaerocult C).

A partir de este medio de cultivo, se recuperaron y se subcultivaron en agar sangre, colonias típicas presuntivas de $P$. multocida, con el fin de obtener cultivos puros (Gutiérrez et al., 2005). A cada uno de los aislados recogidos se les realizó la tinción de Gram, se valoró la capacidad de crecimiento en agar MacConkey y se evaluó las actividades bioquímicas y metabólicas de producción de catalasa (Cowan y Steel, 1993), oxidasa (Weaver y Collins, 1982), motilidad, indol, producción de ornitina descarboxilasa y fermentación de los azúcares D-manitol, D-sorbitol, dulcitol, Larabinosa, D-lactosa, maltosa, D-trehalosa y Dxilosa, mediante procedimientos estándar. Las cepas de referencia empleadas en el presente estudio fueron P. multocida ATCC 10322, 10323, 10325 y 10326.

\section{Serotipificación capsular}

Se realizó según los métodos descritos por Carter y Subpronto (1973) y Carter y Rundell (1975). Las cepas se sembraron en $3 \mathrm{ml}$ de caldo $\mathrm{BHI}$ durante 24 horas, posteriormente el cultivo se centrifugó durante 10 minutos a $15.000 \mathrm{rpm}$, se eliminaron 2,5 $\mathrm{ml}$ del sobrenadante y se adicionó al medio $0,5 \mathrm{ml}$ de la solución de Acriflavina (solución acuosa de acriflavina "Sigma" en una proporción 1:1000), Después de 5 minutos, se consideraba positiva (adscripción al tipo capsular D) la reacción ante la aparición de un precipitado floculento en el medio de cultivo.

Para la detección del tipo capsular A se hizo mediante una modificación del procedimiento no serológico descrito por Rutter (1983), de esta forma, las cepas fueron detectadas por la sensibilidad a la hialuronidasa. Las cepas fueron crecidas en agar sangre durante 24 horas, se preparo una suspensión de una turbidez de 4 , según la escala de McFarland, y se diluyó la muestra 1:5 en agua destilada. Se sembró cada cepa en masa sobre agar $\mathrm{BHI}$, posteriormente, se depositó en el centro de cada placa un disco de papel de filtro estéril, impregnado con una solución de hialuronidasa de testículo de cordero (Sigma), de 5600 unidades por $\mathrm{ml}$, a razón de $10 \mu \mathrm{l}$ por disco. Se incubaron las placas a $37^{\circ} \mathrm{C}$ durante 24 horas. La reacción positiva se manifiesta por la reducción en el tamaño de las colonias de $P$. multocida alrededor del disco.

\section{Caracterización genotípica}

\section{Extracción de ADN mediante el método fenol- cloroformo}

La extracción y purificación del ADN de cada una de las cepas se realizó siguiendo el método fenolcloroformo descrito por Sambrook et al., (1989).

\section{Oligonucleótidos PCR}

Todos los oligonucleótidos empleados en este estudio fueron sintetizados por Roche (España), descritos por Townsend et al., (1998) y Townsed et al., (2001) y se nombran en la tabla 1.

Tabla 1

Descripción de los oligonucleótidos utilizados en este trabajo

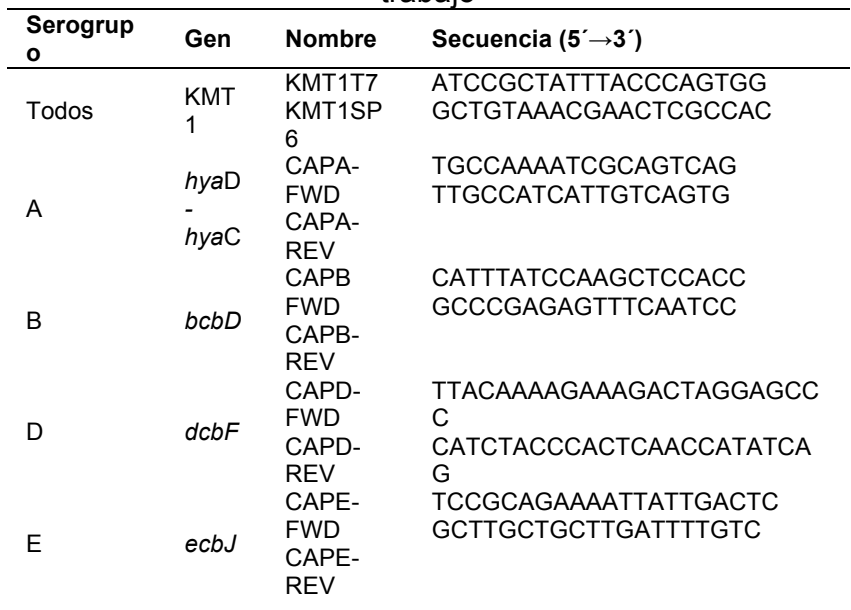

\section{Condiciones de PCR}

En la PCR de especie y tipo capsular, se preparó la siguiente mezcla de reacción: Agua Milli-Q estéril 36,5 $\mu$; Tampón 10x para la Taq polimerasa $5 \mu \mathrm{l}$; MgCl2 (25 mM) 2,5 $\mu$ l; dNTPs ( $25 \mu \mathrm{M}$ cada uno) 0,5 $\mu \mathrm{l}$; Taq ADN polimerasa $(5 \mathrm{U} / \mathrm{ml}) 0,5 \mu \mathrm{l}$; cebador $(20$ $\mu \mathrm{M}) 1 \mu \mathrm{l}$ de cada uno; ADN molde $(1: 10) 3 \mu \mathrm{l}$. 
Volumen final de $50 \mu \mathrm{l}$. Los componentes se añadieron en el orden descrito, en un tubo de PCR estéril, manteniendo la mezcla siempre en hielo. Todas las amplificaciones fueron realizadas en "MastercycleGradient" (Eppendorf, USA). Para la amplificación del gen KMT1 se empleó el siguiente programa de PCR: una desnaturalización inicial a $95^{\circ} \mathrm{C}$ por $5 \mathrm{~min}$, seguido por 30 ciclos de desnaturalización a $95^{\circ} \mathrm{C}$ por $30 \mathrm{~s}$ hibridación $55^{\circ} \mathrm{C}$ por $30 \mathrm{~s}$; elongación $72^{\circ} \mathrm{C}$ por 30 seg y una elongación final $72^{\circ} \mathrm{C}$ por 5 min.

Una vez detectadas las cepas de $P$. multocida mediante la PCR específica de especie, se realizó a partir de estas, una PCR para identificar los tipos capsulares (A, B, D y E) presentes, diseñada por Townsend et al., (2001), siendo modificada, empleándose los ciclos de PCR descritos en la tabla 2. Los productos amplificados fueron separados por electroforesis en geles de agarosa al $1 \%$ y visualizados por tinción con bromuro de etidio.

Tabla 2

Programa de PCR empleado en la amplificación de los tipos capsulares de $P$. multocida

\begin{tabular}{|c|c|c|c|c|c|}
\hline \multirow{2}{*}{$\begin{array}{l}\text { Tipos } \\
\text { capsul } \\
\text { ares }\end{array}$} & \multirow{2}{*}{$\begin{array}{c}\text { Desnaturali } \\
\text { zación } \\
\text { inicial }\end{array}$} & \multicolumn{3}{|c|}{ Amplificación } & \multirow{2}{*}{$\begin{array}{c}\text { Elonga } \\
\text { ción } \\
\text { final }\end{array}$} \\
\hline & & $\begin{array}{l}\text { Desnaturali } \\
\text { zación }\end{array}$ & $\begin{array}{c}\text { Hibrida } \\
\text { ción }\end{array}$ & $\begin{array}{c}\text { Elonga } \\
\text { ción }\end{array}$ & \\
\hline A & \multirow{3}{*}{$\begin{array}{c}5 \min 95^{\circ} \mathrm{C} \\
1 \text { ciclo }\end{array}$} & $\begin{array}{c}30 \mathrm{seg} \\
95^{\circ} \mathrm{C} \\
24 \text { ciclos }\end{array}$ & $\begin{array}{c}30 \mathrm{seg} \\
61^{\circ} \mathrm{C}\end{array}$ & $\begin{array}{l}1 \min \\
72^{\circ} \mathrm{C}\end{array}$ & \multirow{3}{*}{$\begin{array}{l}5 \mathrm{~min} \\
72^{\circ} \mathrm{C} \\
1 \text { ciclo }\end{array}$} \\
\hline B y E & & $\begin{array}{c}30 \mathrm{seg} \\
95^{\circ} \mathrm{C} \\
30 \text { ciclos }\end{array}$ & $\begin{array}{l}30 \mathrm{seg} \\
55^{\circ} \mathrm{C}\end{array}$ & $\begin{array}{l}30 \mathrm{seg} \\
72^{\circ} \mathrm{C}\end{array}$ & \\
\hline D & & $\begin{array}{c}30 \mathrm{seg} \\
95^{\circ} \mathrm{C} \\
19 \text { ciclos }\end{array}$ & $\begin{array}{l}30 \mathrm{seg} \\
57^{\circ} \mathrm{C}\end{array}$ & $\begin{array}{c}30 \mathrm{seg} \\
72^{\circ} \mathrm{C}\end{array}$ & \\
\hline
\end{tabular}
tabla 1 .

\section{RESULTADOS Y DISCUSIÓN}

\section{Identificación fenotípica}

De un total de 181 muestras, se logró recuperar a partir de los cultivos, en medio selectivo, 145 aislamientos presuntivos de $P$. multocida, junto a estos, otras 76 cepas, obtenidas entre los años 1987-1988, fueron reconfirmadas. En ambos casos, se consideraron presuntivas, al atender a características macroscópicas típicas, tales como colonias lisas, de color blanco grisáceo, no hemolíticas, con un acusado aspecto mucoso y pegajosas, además los cultivos desprendían un olor dulzón y su crecimiento masivo provocaba el oscurecimiento del medio de cultivo. De esta forma, se evidencia que el medio de cultivo empleado favoreció la recuperación y crecimiento de $P$. multocida, lo que corrobora los resultados obtenidos por Avril et al., (1990).

Las colonias presuntivas fueron seleccionadas, atendiendo inicialmente a su morfología bacilar y/o cocobacilar, tinción Gram negativa, producción de oxidasa y catalasa, producción de ácido a partir del manitol, así como a la incapacidad de crecer sobre agar MacConkey (Cowan y Steel, 1993). A estas valoraciones bioquímicas iniciales, se les sumo posteriormente otras con el fin de determinar la especie presente. De esta forma, todas las cepas, no presentaron hemólisis sobre agar sangre, fueron indol positivo, fermentaron la L-arabinosa, Dlactosa,
D-trehalosa, D-xilosa y maltosa, diferenciándose sólo por la capacidad de fermentar la trehalosa y por la descarboxilación de la ornitina (ODC), ya que sólo 43 cepas de las 221 analizadas presentaron un resultado negativo. Estos resultados concuerdan con los obtenidos en otros estudios, lo que permite ratificar la adscripción de estos aislados como $\mathrm{P}$. multocida (Blackall et al., 1995; Jamaludin et al., 2005). Igualmente, y con el fin de establecer la subespecie presente entre las cepas analizadas, se realizó un análisis bioquímico para determinar la capacidad de fermentar el sorbitol y el dulcitol, lo que permite diferenciar entre las tres subespecies que conforman esta especie como se describe en la tabla 3 (Blackall et al., 1998; Pertersen et al., 2001), siendo el $100 \%$ de los aislados, sorbitol positivo y dulcitol negativo, por tanto se identificaron como $P$. multocida subsp. multocida.

Tabla 3

Diferenciación bioquímica de las subespecies de $P$. Multocida

\begin{tabular}{|c|c|c|}
\hline $\begin{array}{c}\text { Subespecies } \boldsymbol{P} . \\
\text { multocida }\end{array}$ & $\begin{array}{c}\text { Fermentación } \\
\text { de sorbitol }\end{array}$ & $\begin{array}{c}\text { Fermentación } \\
\text { de dulcitol }\end{array}$ \\
\hline $\begin{array}{c}\text { P. multocida } \\
\text { subsp. Multocida }\end{array}$ & + & - \\
\hline $\begin{array}{c}\text { P. multocida } \\
\text { subsp. Gallicida }\end{array}$ & + & + \\
\hline $\begin{array}{c}\text { P. multocida } \\
\text { subsp. Séptica }\end{array}$ & - & - \\
\hline
\end{tabular}


De esta forma, se demostró mediante la determinación bioquímica, que la subespecie multocida es la única de las tres subespecies que se halla presente en las muestras clínicas de pulmones de cerdos; esto concuerda con numerosos estudios de caracterización de cepas de $P$.multocida realizados por diversos autores (Mutters et al., 1985, Snipes et al., 1990, Bisgaard et al., 1991, Korbel et al., 1992, Fegan et al., 1995, Blackall et al., 1997, Mohan et al., 1994, Pertersen et al., 2001). La detección de las cepas $P$. multocida tipo capsular D se determinó por la capacidad de autoaglutinación en presencia de acriflavina (Carter y Subpronto, 1973). Del total de cepas analizadas (221), sólo 3 (el 1,4\%) fueron positivas, este resultado fue contrastado con los obtenidos a partir de las cepas de referencia usadas en el presente estudio (figura 1), de las cuales sólo la cepa ATCC 10325 tipo capsular D demostró una reacción positiva.

Figura 1

Resultados de la detección de acriflavina obtenidos a partir de las cepas de referencia P. multocida tipo capsular A (ATCC 10322), B (ATCC 10324) y D (ATCC 10325)

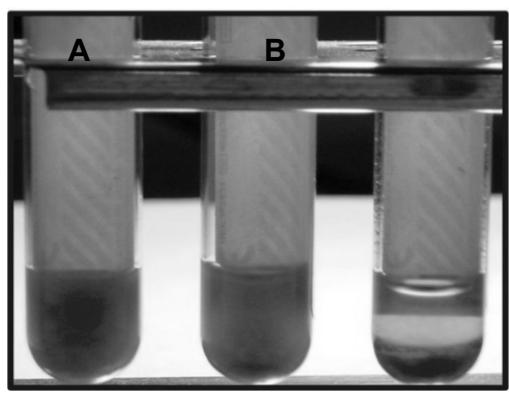

Como se puede observar en la figura 2 , en la determinación del tipo capsular $\mathrm{A}$, el efecto observado sobre el crecimiento bacteriano consistió en la disminución del tamaño y mucosidad de las colonias que se encontraban alrededor del disco de hialuronidasa (Carter et al., 1975). Este efecto se observó en el $98.6 \%$ (218 cepas) de las cepas analizadas, por lo que fueron clasificadas como $P$. multocida tipo capsular A. De igual forma que en la prueba anterior, las cepas de referencia fueron empleadas como controles, y sólo resultó positiva la cepa P. multocida ATCC 10322 tipo capsular A. Los resultados de las pruebas no serológicas permitieron agrupar inequívocamente los aislados de $P$. multocida subsp. multocida en los tipos capsulares $A$ y $D$.

Figura 2

Prueba de sensibilidad a la hialuronidasa observada en la cepa de $P$. multocida ATCC 10322 tipo capsular A.

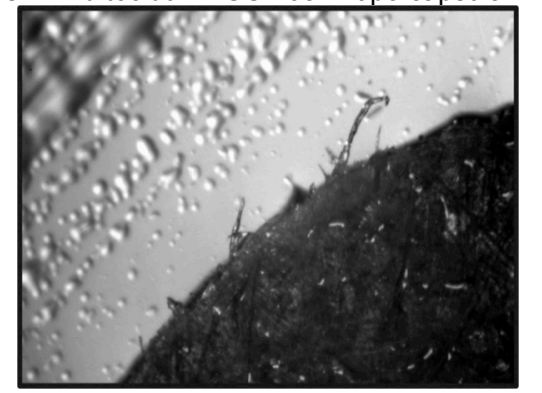

El hecho de que casi la totalidad de las cepas fueran tipo capsular A, coincide con lo observado por otros autores para este tipo de bacteria procedente de las lesiones neumónicas (Pijoan et al., 1983, Prescott et al., 1984; López et al., 1988), además es usual encontrar estos dos tipo capsulares en cerdos tanto sanos (Lariviere et al., 1992), como enfermos (Iwamatsu y Sawada, 1988; Djordjevic et al., 1998; Dziva et al., 2000).

\section{Identificación genética}

La determinación de la especie mediante el análisis de PCR permitió establecer que la totalidad de los aislados pertenecían a la especie $P$. multocida, amplificándose a partir del ADN de cada uno de ellos una banda de aproximadamente $460 \mathrm{pb}$ (figura 3), este fragmento correspondió en tamaño con los obtenidos a partir de las cepas de referencia (Townsend et al., 1998).

Figura 3

Electroforesis en gel ( $1 \%$ de agarosa) del producto de PCR específico de especie para algunos de los aislados de $P$. multocida, utilizando los cebadores KMT1T7 y KMT1SP6

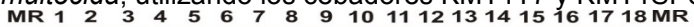

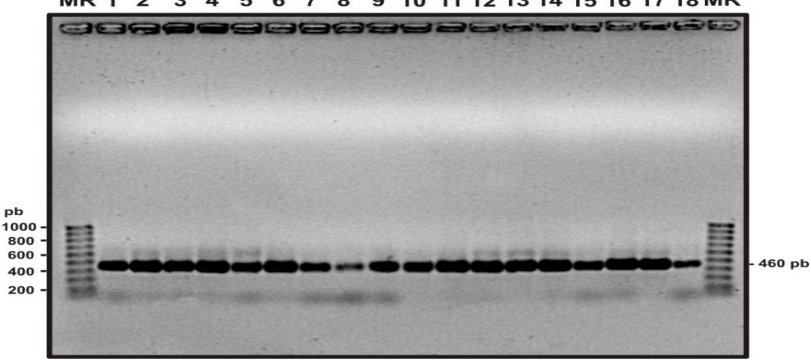

Corresponden cada uno de los carriles a: $P$. multocida ATCC 10322 tipo A (1), $P$. multocida ATCC 10323 tipo B (2), P. multocida ATCC 10325 tipo D (3), P. multocida ATCC 10326 tipo E (4), aislados clínicos de P. multocida (5-18). También se ha ATCC 10326 tipo E (4), aislados "100 pb Molecular Ruler" (MR). La imagen que se incorporado el marcador de tamaño "100 pb Molecular Ruler" (MR). La imagen que se muestra es el negativo respecto a la fotografía del gel. 
Mediante la prueba de PCR se amplificaron los genes hyaD-hyaC para el grupo capsular $\mathrm{A}$, y el gen $d c b F$ para el grupo $D$, cuyos productos de amplificación tuvieron un peso molecular esperado de $1044 \mathrm{pb}$ y $657 \mathrm{pb}$, respectivamente, siendo correspondiente con el tamaño de la banda obtenido para las cepas de referencia A y D (Figura $4 \mathrm{~A}$ y $4 \mathrm{~B})$.

Del total de aislados analizados, el 98,6 \% (218 cepas) corresponde al tipo capsular A y el restante 1,4 \% (3 cepas) al tipo capsular D. Esta proporción, concuerda con otros estudios realizados, en los que se han identificado cepas de $P$. multocida tipo capsular A y D como agentes causales de neumonías y rinitis atrófica en cerdos, respectivamente (Glorioso et al., 1982; Letellier et al., 1991; Pijoan, 1992; Shewen y Rice, 1993; Akerman et al., 1994; Al Haddawi et al., 2002; Townsend et al., 2001; Jamaludin et al., 2005; Shivachandra et al., 2008).
Figura 4

(A) Electroforesis en gel ( $1 \%$ de agarosa) del producto de PCR de la caracterización capsular de las cepas de referencia de $P$. multocida subsp multocida tipo A (4), B (3), D (2) y E. (B)

Algunas cepas de $P$. multocida subsp. multocida caracterizadas mediante PCR como tipo capsular A, cular Ruler" (MR).

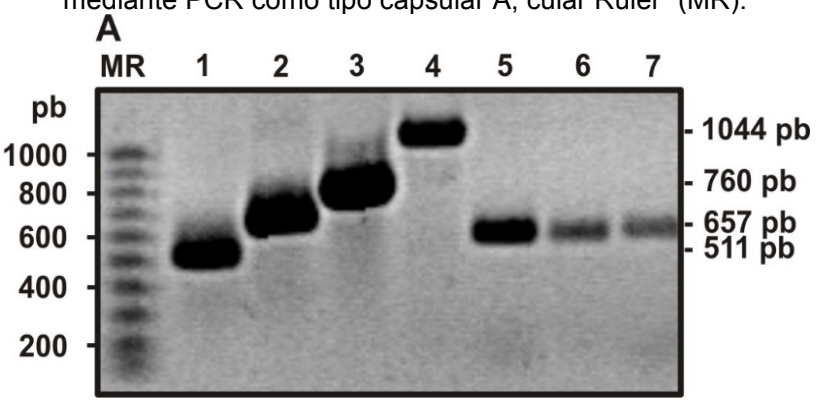

B

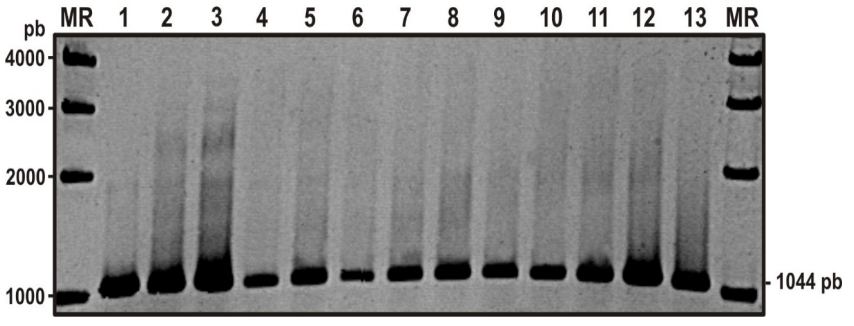

Corresponden cada uno de los carriles: (A) P. multocida subsp multocida tipo A (4), B (3), D (2) y E (1), utilizando los cebadores, CAPA-FWD y CAPA-REV, CAPB-FWD y CAPB-REV, CAPD-FWD y CAPD-REV, CAPE-FWD y CAPE-REV. (B) P. multocida subsp. Multocida, tipo capsular A, utilizando los cebadores, CAPA-FWD y CAPA-REV siendo, P multocida subsp. multocida ATCC 10322 tipo capsular A (1), aislados de P. multocida subsp. multocida tipo capsular A (2-18) Se ha incorporado marcadores de $\begin{array}{lllllll}\text { multocida subsp. multocida tipo capsular A (2-18). Se ha incorporado marcadores de } \\ \text { tamaño "1 } \mathrm{kb} & \text { (A) y } 100 \mathrm{pb} & \text { (B) Molecular Ruler" } & \text { (MR). }\end{array}$

\section{CONCLUSIONES}

Se identificaron y caracterizaron 221 cepas como Pasteurella multocida subsp multocida a partir de los estudios fenotípicos y genéticos realizados a las muestras clínicas de pulmones neumónicos de cerdos, recogidas durante los periodos 1987-1988 y 2003-2004 en el matadero de León. Los perfiles bioquímicos observados en las cepas aisladas fueron idénticos, solo diferenciándose algunos de ellos, por la capacidad de fermentar la trehalosa (40 cepas) y la presencia de ODC (3 cepas), lo cual puede indicar que estas cepas puedan ser tomadas como variantes.
La determinación de la capacidad de fermentar el sorbitol y el dulcitol permitió establecer claramente que todos las cepas aisladas se adscriben a la subespecie Pasteurella multocida subsp. multocida. La mayoría de las cepas fueron identificadas mediante métodos no serológicos como tipo capsular A y sólo 3 cepas como tipo capsular D.

Mediante PCR se logró confirmar los resultados fenotípicos obtenidos en la identificación de la especie y tipo capsular, ratificándose que todas ellas son Pasteurella multocida y diferenciándose en dos tipos capsulares el A y D.

\section{REFERENCIAS BIBLIOGRÁFICAS}

Ackermann, M., DeBey M., Register K., Larson, D., Kinyon J. Tonsil and turbinate colonization by toxigenic and nontoxigenic strains of Pasteurella multocida in conventionally raised swine. (1994). Journal of Veterinary Diagnostic Investigation. 6: 375377.
Avril, J. L., Donnio, P. Y., Pouedras, P. Selective Medium for Pasteurella multocida and Its Use to Detect Oropharyngeal Carriage in Pig Breeders. (1990). Journal of Clinical Microbiology. 28(6): 1438-40. 
Vera L. Yanedt A. et al. /@limentech, Ciencia y Tecnología Alimentaria 13(2015) 5-12

Bisgaard, M., Houston, S. B., Mutters, R., Stenzel, A. Reclassification of German, British and Dutch isolates of socalled Pasteurella multocida obtained from pneumonic calf lungs. (1991). Veterinary Microbiology. 26, 115-124.

Blackall, P. J., Fegan, N., Chew, G. T. I., Hampson, D. J. Population structure and diversity of avian isolates of Pasteurella multocida from Australia. (1998). Microbiology. 144: 279-289.

Blackall, P.J., Pahoff, J.L., Bowles, R. Phenotypic characterisation of Pasteurella multocida isolates from Australian pigs. (1997). Veterinary Microbiology. 57: 355-360.

Blackall, P.J., Pahoff, J.L., Marks, D., Fegan, N., Morrow, C.J. Characterisation of Pasteurella multocida isolated from fowl cholera outbreaks on turkey farms. (1995). Australian Veterinary Journal. 72: 135-138.

Carter, G. R., Rundell, D. W. Identification of type A strains of Pasteurella multocida using Staphylococcal hyaluronidase. (1975). Veterinary Record. 87: 343.

Carter, G.R., Subpronto, P. Identification of type D strains of Pasteurella multocida with acriflavine. (1973). American Journal of Veterinary Research. 34: 293-294.

Cowan, S.T., Steel, K.J. Manual for the Identification of Medical Bacteria. Third edition Cambridge Univ. Press, UK: In: Barrow, G. I., Feltham, R. K. A. (Eds.).(1993). p117-148.

Djordjevic, S. P., Eamens, G. J., Ha, H., Walker, M. J., Chin, J. C. Demonstration that Australian Pasteurella multocida isolates from sporadic outbreaks of porcine pneumonia are nontoxigenic (toxA-) and display heterogeneous DNA restriction endonuclease profiles compared with toxigenic isolates from herds with progressive atrophic rhinitis. (1998). Journal Medical Microbiology. 47: 679-688.

Dziva, F., Christensen, H., van Leengoed, L. A., Mohan, K., Olsen, J. E. Differentiation of Pasteurella multocida isolates from cases of atrophic rhinitis in pigs from Zimbabwe by RAPD and ribotyping. (2004). Veterinary Microbiology. 102: 117-122.

Fegan, N., Blackall, P. J., Pahoff, J. L. Phenotypic characterization of Pasteurella multocida isolates from Australian poultry. (1995). Veterinary Microbiology. 47: 281286.
Garrity, G. M. Bergey's Manual of Systematic Bacteriology. Second edition. Volumen two. Michigan State University: Editorial Springer. 2005, p850-865.

Glorioso, J. C., Jones, G. W., Rush, H. G., Pentler, L. J., Darif C. A., Coward, J. E. Adhesion of type A Pasteurella multocida to rabbit pharyngeal cells and its possible role in rabbit respiratory tract infections. (1982). Infection and Immunity. 35: 1103-1109.

Gutiérrez, C. B., Vera, Y. A., Del rio, G. M., Rodríguez, F. E. Procesos producidos por Pasteurella multocida. (2005). Suis. 14: 30-41.

Iwamatsu, S., Sawada, T. Relationship between serotypes, dermonecrotic toxin production of Pasteurella multocida isolates and pneumonic lesions of porcine lung. (1988). Nippon Juigaku. Zasshi 50: 1200-1206.

Jamaludin, R., Blackall, P. J., Hansen, M. F., Humphrey, S., Styles, M. Phenotypic and genotypic characterisation of Pasteurella multocida isolated from pigs at slaughter in New Zealand. (2005). New Zealand Veterinary Journal. 53(3): 203207.

Kasten, R. W., Wakenell, P. S., Ahmad, S., Yilma, T. D., Hirsh, D. C. Lack of protection against avian cholera by vaccination with recombinant P6-like protein from Pasteurella multocida. (1997). Avian Diseases. 41: 972-976.

Korbel. R., Gerlach, H., Bisgaard, M., Hafez, H. M. Further investigations on Pusteurellu multocidu infections in feral birds injured by cats. (1992). Journal of Veterinary Medicine. 39: 1018.

Lariviere, S., Leblanc, L., Mittal, K. R., y Martineau, G. P. Characterization of Pasteurella multocida from nasal cavities of piglets from farms with or without atrophic rhinitis. (1992). Journal Clinical Microbiology. 30: 1398-1401.

Letellier, A., Dubreuil, D., Roy, G., Fairbrother, J. M., Jacques. M. Determination of affinity of Pasteurella multocida isolates for porcine respiratory tract mucus, and partial characterization of the receptors. (1991). American Journal of Veterinary Research. 52:34-39.

López, A. G., Polanco, G., De Mora, Y. P., De Aponte, F. M. Tipos capsulares A y D de Pasteurella multocida de origen 
porcino. (1988). Revista de la Facultad de Ciencias Veterinarias U.C.V. 35 (1-4): 21-28.

Mohan, K., Sadza, M., Madsen, M., Hill, F.W.G., Pawandiwa, A. Phenotypic characterization of Zimbabwean isolates of Pasteurella multocida. (1994). Veterinary Microbiology. 38: 351-357.

Mutters, R., Ihm, P., Pohl, S., Fredericksen, W., Mannheim, W. Reclassification of the genus Pasteurella Trevisan 1887 on the basis of deoxyribonucleic acid homology, with proposals for the new species Pasteurella dagmatis, Pasteurella canis, Pasteurella stomatis, Pasteurella anatis, and Pasteurella langaa. (1985). International Journal of Systematic Bacteriology. 35: 309-322.

Nielsen, J. P., Frederiksen, W. Atrophic rhinitis in pigs caused by a human isolate of toxigénica Pasteurella multocida. 1990. In: International pig veterinary society congress, 11. Proceedings, 1989, p75.

Petersen, K. D., Christensen, H., Bisgaard, M., Olsen, J. E. Genetic diversity of Pasteurella multocida isolated from fowl cholera as demonstrated by ribotyping, 16S rRNA and partial atpD sequence comparisons. (2001). Microbiology. 147: 2739_ 2748.

Pijoan, C.. Pneumonic Pasteurellosis. 7 ed. lowa; Wolfe Publshing Ltd: In Leman, A. (Eds) Diseases of Swine. 1992, p552-559.

Pijoan, C., Morrison, R. B., Hilley, H. D. Serotyping of Pasteurella multocida Isolated from Swine Lungs Collected at Slaughter. (1983). Journal of Clinical Microbiology. 17(6): 1074-1076.

Prescott, J.F, Bhasin, J.L., Sanford, S. E. Serotypes and antimicrobial susceptibility of Pasteurella multocida isolated from cattle and pigs in Ontario. (1984). The Canadian Veterinary Journal. 25: 117-118.
Rhoades, K. R., Rimler, R. B. Fowl Cholera. In: Pasteurella and Pasteurellosis. London: Academic Press Limited, 1989, p95144.

Rutter, J. M. Virulence of Pasteurella multocida in athrophic rhinitis of gnotobiotic pigs infected with Bordetella bronchiseptica. (1983). Research in Veterinary Science. 34: 285-287.

Sambrook J., Frisch EF, Maniatis T. Molecular cloning a laboratory manual. 2 edition. New York: Greene Publishing Associates and John Wiley \& Sons. 1989.

Shewen, P. E., Rice Conlon, J. A Pathogenesis of bacterial infections in animals, 2nd. Pasteurella. In C. L. Gyles and C. O. Thoen (ed.), ed. Iowa State University Press, Ames. 1993, p216-225.

Shivachandra, S. B., Kumar, A. A., Chaudhuri, Molecular characterization of Avian strains of Pasteurella multocida serogroup-A: 1 based on amplification of repetitive regions by PCR. (2008).Comparative Immunology, Microbiology \& Infectious Diseases. 31(1): 47-62.

Sneath, P. H. A., Stevens, M. Actinobacillus rossii sp. nov., Actinobacillus seminis sp. nov., nom. rev., Pasteurella bettii sp. nov., Pasteurella lymphangitidis sp. nov., Pasteurella mairi sp. nov., and Pasteurella trehalosi sp. Nov. (1990). International Journal of Systematic Bacteriology. 40: 148-153.

Townsend, K. M., Boyce, J. D., Chung, J. Y., Frost, A. J., Adler, B. Genetic organization of Pasteurella multocida cap loci and development of a multiplex capsular PCR typing system. (2001). Journal of Clinical Microbiology. 39: 924-929.

Townsend, K. M., Frost, A. J., Lee, C. W.: Papadimitriou, J. M., Dawkins, H. J. Development of PCR assays for species- and type-specific identification of Pasteurella multocida isolates. (1998). Journal of Clinical Microbiology. 36: 1096-1100.

Weaver N, Collins M. Evaluation of seven commercial oxidase test products with Pasteurella. (1982). American Journal of Veterinary Research. 43 (2):363-4.

\section{AGRADECIMIENTOS}

Este trabajo ha sido realizado y subvencionado, gracias a la colaboración del Departamento de Sanidad Animal, área de Microbiología e Inmunología de la Universidad de León, España. 